\title{
THE INFLUENCE OF VEHICLE MAINTENANCE CONDITIONS ON CHOSEN ELECTRIC PARAMETERS OF STARTER DURING COMBUSTION ENGINE START-UP
}

\begin{abstract}
Necessary mechanical energy needed for initiation of self-dependent combustion engine work is transferred by crankshaft driving using an electrical starter. Changes of values of the static resistant moment and start-up resistant moment in the engine influence current input by the electric starter during start-up of the combustion engine. Overloads observed in the vehicle electric power system are the results of high value of current intensity input by the electric starter. It seems very important to find the answer how the vehicle maintenance conditions influence the chosen working electric parameters of the starter during the combustion engine start-up. This article presents the results of investigations of starting working electric parameters during a combustion engine start-up, made during the vehicle maintenance.
\end{abstract}

\section{Introduction}

Necessary mechanical energy needed for initiation of self-dependent combustion engine work is transferred by crankshaft driving using an electrical starter supplied from the accumulator in modern vehicles. Initiation of the engine start-up begins when the operator applies voltage at the starter. Interconnection of the pinion with the flywheel gear ring of engine crankshaft circle occurs. Passing from standstill to motion state of elements and groups of engine needs overcoming a great resistance of static friction forces from the electric starter. Later the engine start-up resistant moment has less value than at the starting point of the movement. This moment is characterized by significant variability connected with kinematics of the pistons to-and-fro motion and changeable pressure during air-fuel mixture compression and expansion in the engine cylinders $[3,4,5]$.

Changes of values of static resistant moment and start-up resistant moment influence the current run input by the electric starter during start-up of the combustion engine. On the beginning of the engine start-up the maximal value of current intensity input by the electric starter (with electric power 3-4,5 kW) can exceed $300 \mathrm{~A}$. During the next stage of start-up current intensity drops more than twice. Overloads observed in the vehicle electric power system are the results of high value of current intensity input by the electric starter. The voltage drops corresponding with them can cause abnormalities in the vehicle electronic systems work. The value of current intensity input by the electric starter during the engine startup depends on many factors such as: technical state of the engine start-up system, state of the accumulator load, properties of lubricant, the length of pauses in the vehicle operation, engine temperature etc. $[1,3,6]$.

The user of the vehicle has an influence on some of these factors but most of them are relative only to external conditions of the vehicle maintenance. It seems very important to find the answer how the vehicle maintenance conditions influence working electric parameters of the starter during the combustion engine start-up. It is not only important for a vehicle operator but, first of all, for a designer of modern combustion engine start-up systems. This article presents the results of investigations made during the engine maintenance.

\section{Research methodology}

The researches included the 443115142723 starter produced by the Czech company MAGNETON. It is an electric series motor designed for a short-term operation. The pinion of the starter which initiates the motion of the engine crankshaft circle is drown out electromagnetically by a switch with two windings: retracting and supporting. When the starter is switched on both windings work. When the current flows along the starter winding the retracting winding is switched off. Constant work of the starter cannot be longer than 5 seconds. Maximal current input by the starter is $140 \mathrm{~A}$ and minimal rotational speed is $5000 \mathrm{rpm}$ during a test without loading. On the other hand current input by the starter is 550-600 A, minimal rotational speed is $1500 \mathrm{rpm}$ and voltage drop on the starter clamp is $10 \mathrm{~V}$ during a test with loading. The chosen technical data of the starter are shown in tab. 1.

The investigation starter is installed in the 4-cylinder diesel engine 4 CT 90 . This engine is produced by the engine factory "Andoria" located in Andrychów, Poland. The engine displacement: indirect injection, $2.417 \mathrm{dm}^{3}$, stroke/diameter 95/90, maximum power: $63.5 \mathrm{~kW}$ at $4100 \mathrm{rpm}$, maximum torque: $195 \mathrm{Nm}$ at $2500 \mathrm{rpm}$. This engine was equipped with the injection pump MOTORPAL Jihlava type PP4M7P1g 3176, produced in the Czech Republic. The 4CT90 engine is installed in a delivery truck (maximum

\footnotetext{
* Paweł Droździel

Department of Machine Design, Mechanical Faculty, Lublin University of Technology, ul. Nadbystrzycka 36, 20-618 Lublin, POLAND,

E-mail: p.drozdziel@pollub.pl
} 
Technical data of the starter 443115142723 company MOTORPAL

\begin{tabular}{|l|c|}
\hline Nominal voltage [V] & 12 \\
\hline Nominal power [kW] & 3 \\
\hline Moment on pinion [Nm] & $\min 44.1$ \\
\hline Rotations on nominal Power [rpm] & $1700^{+100}$ \\
\hline Voltage on „30” starter clamp on nominal power [V] & 10 \\
\hline Current of starter without loading [A] & 140 \\
\hline The direction of rotations & Right \\
\hline Wright [kg] & 5.3 \\
\hline Number of teeth in pinion [-] & 9 \\
\hline Module pinion pitch [-] & 3 \\
\hline
\end{tabular}

authorized total weight $<3.5$ t) LUBLIN III. The investigated vehicle was maintained by the Polish Post in Lublin Province during spring, summer and autumn seasons.

A special recorder was constructed to register selected parameters of LUBLIN III operation and activity of the 4CT90 engine and its starter. The following parameters were recorded: time and date of switching on electrical supply in the vehicle, number of crankshaft revolutions and drive shaft, pressure and temperature of the engine oil, coolant temperature, toothed bar position of the injection pump. The starter electric parameters were recorded: intensity of the current consumed by the starter at the engine start-up and voltage applied at the starter. The current consumed by the starter as well as voltage at the starter were recorded every $25 \mathrm{~ms}$ from the very beginning of the engine start-up cycle, after the value of the starter current had exceeded the threshold (50A). All the parameters were transferred to a PC computer where they were processed by the programme converting raw data into text-saved measurement results. Then they were transmitted to other computer programmes to analyse the data [2].

\section{Statistical analysis of experimental results}

The results of the research on selected parameters of the LUBLIN III vehicle operation, the 4CT90 engine start-up and electric parameters of its starter were analysed by a computer programme STATISTICA. The following electric and working parameters of the investigated starter: maximal current intensity $\left(I_{\max }\right.$ in A) in a first step of start-up, voltage $\left(U_{\max }\right.$ in $\left.\mathrm{V}\right)$ at the maximal current intensity, power $\left(P_{\max }\right.$ in $\left.\mathrm{W}\right)$ consumed by the starter at the maximal current intensity, mean current intensity ( $I_{\text {mean }}$ in A), which occurs when the starter drives the engine crankshaft during the start-up, mean voltage $\left(U_{\text {mean }}\right.$ in $\left.\mathrm{A}\right)$ and mean power $\left(P_{\text {mean }}\right.$ in $\mathrm{W})$, time $\left(t_{\text {start }}\right.$ in sec) of the engine start-up and time ( $t_{\text {work }}$ in sec) work of starter were distinguished.

The time of the engine start-up is stated from the moment of applying the voltage on the starter to the moment when current intensity input by the starter reaches the value which appears during work without loading. The time of the starter work is connected with time of applying the voltage at the starter.

The histogram of maximal current intensity $I_{\max }$ in the first step of start-up is presented in Figure 1. This bar chart was approximated using an extreme value distribution with the following coefficients: position - 292.74; scale - 46.392. Fig. 2 presents a bar chart of the mean current intensity $I_{\text {mean }}$, which occurs when the starter drives the engine crankshaft during the start-up. This bar chart was approximated using the extreme value distribution with the following coefficients: position - 144.33; scale -3.004 .

The histogram of power $P_{\max }$ consumed by the starter at the maximal current intensity is presented in Figure 3. This bar chart was approximated using a lognormal distribution with the following coefficients: scale - 7.806; shape - 0.1379. Fig. 4 presents the bar chart of the mean power $P_{\text {mean }}$ consumed by the starter, which occurs when the starter drives the engine crankshaft during the start-up. This bar chart was approximated using the normal distribution.

The histogram of time of the engine start-up $t_{\text {start }}$ is presented in Fgure 5. This bar chart was approximated using an extreme value distribution with the following coefficients: position -0.3275 ; scale -0.0874 .

Further part of the data analysis deals with preparing the matrix of the correlation coefficients $r$ between the specified starter para-

Statistical parameters of analyzed variables

Tab. 2

\begin{tabular}{|l|c|c|c|c|c|c|c|c|c|}
\hline Random variable & Mean value & $\begin{array}{c}\text { Standard } \\
\text { deviation }\end{array}$ & Median & Mode & $\begin{array}{c}\text { Mean } \\
\text { error }\end{array}$ & Skewness & Kurtosis & $\begin{array}{c}\text { Maximal } \\
\text { value }\end{array}$ & $\begin{array}{c}\text { Minimal } \\
\text { value }\end{array}$ \\
\hline Max current $I_{\text {max }}[\mathrm{A}]$ & 318.15 & 52.73 & 314.00 & 286.00 & 1.565 & 0.354 & -0.399 & 484.00 & 188.00 \\
\hline Max voltage $U_{\max }[\mathrm{V}]$ & 7.84 & 0.60 & 7.86 & 7.86 & 0.017 & -0.225 & 0.146 & 10.20 & 6.00 \\
\hline Max power $P_{\max }[\mathrm{W}]$ & 2477.70 & 341.14 & 2449.44 & 2350.92 & 10.126 & 0.304 & 0.000 & 3801.60 & 1515.00 \\
\hline Mean current $I_{\text {mean }}[\mathrm{A}]$ & 146.25 & 5.05 & 145.00 & 146.00 & 0.178 & 3.046 & 13.219 & $180 ; 00$ & 139 \\
\hline Mean voltage $U_{\text {mean }}[\mathrm{V}]$ & 9.32 & 0.36 & 9.36 & 9.44 & 0.012 & -0.446 & 0.572 & 10.39 & 7.72 \\
\hline Mean power $P_{\text {mean }}[\mathrm{W}]$ & 1362.56 & 55.06 & 1363.68 & 1368.80 & 1.945 & -0.057 & 0.996 & 1582.63 & 1134.84 \\
\hline Time $t_{\text {start }}[\mathrm{sec}]$ & 0.379 & 0.165 & 0.350 & 0.350 & 0.004 & 5.284 & 38.238 & 0.100 & 2.300 \\
\hline Time $t_{\text {work }}[\mathrm{sec}]$ & 0.487 & 0.206 & 0.425 & 0.400 & 0.006 & 3.830 & 23.307 & 0.125 & 2.700 \\
\hline
\end{tabular}




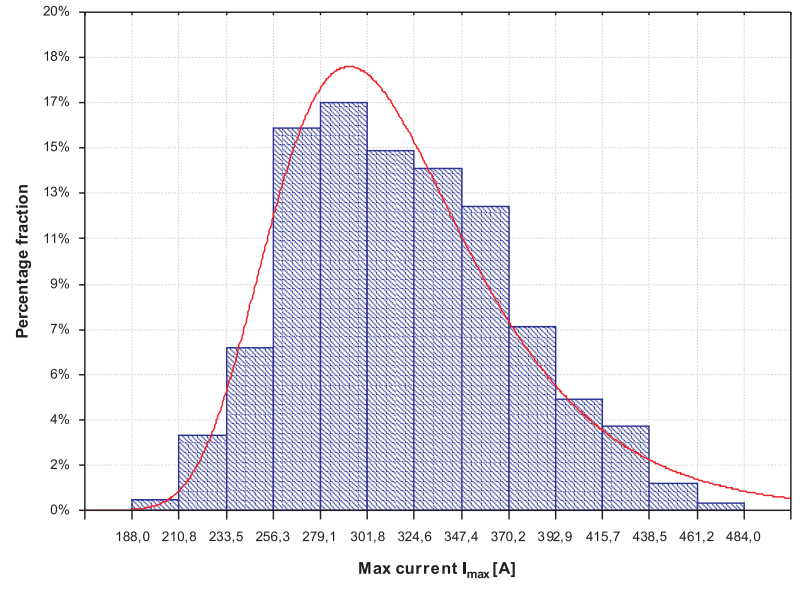

Fig. 1 Statistical distribution of maximal current intensity $I_{\max }$ in first step of start-up

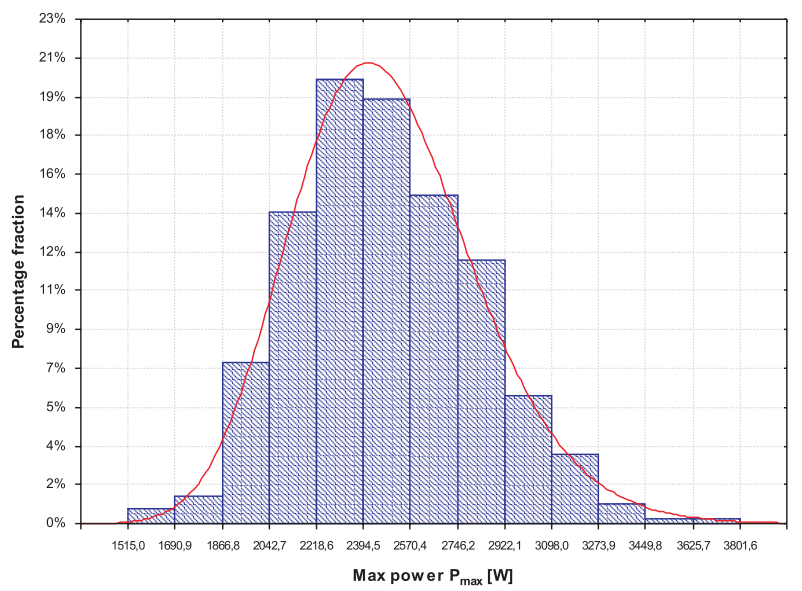

Fig. 3 Statistical distribution of power consumed $P_{\max }$ by the starter at the maximal current intensity

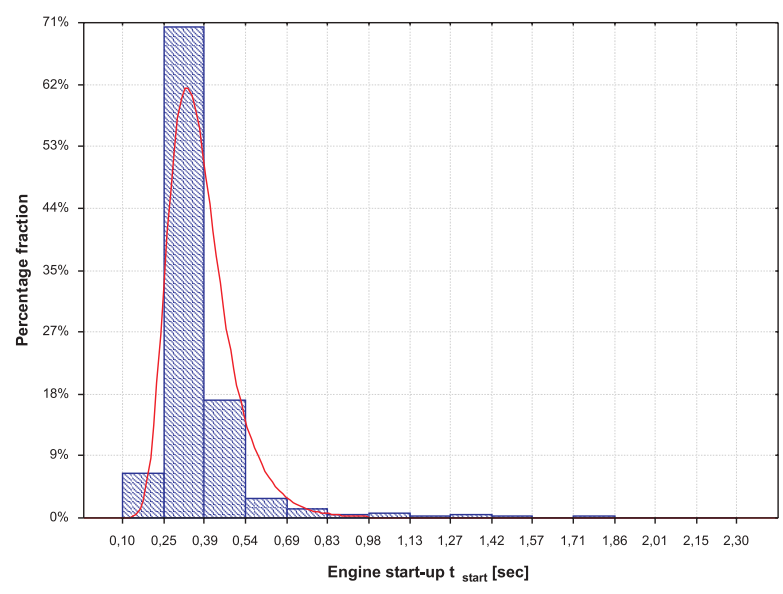

Fig. 5 Statistical distribution of the engine start-up $t_{\text {start }}$

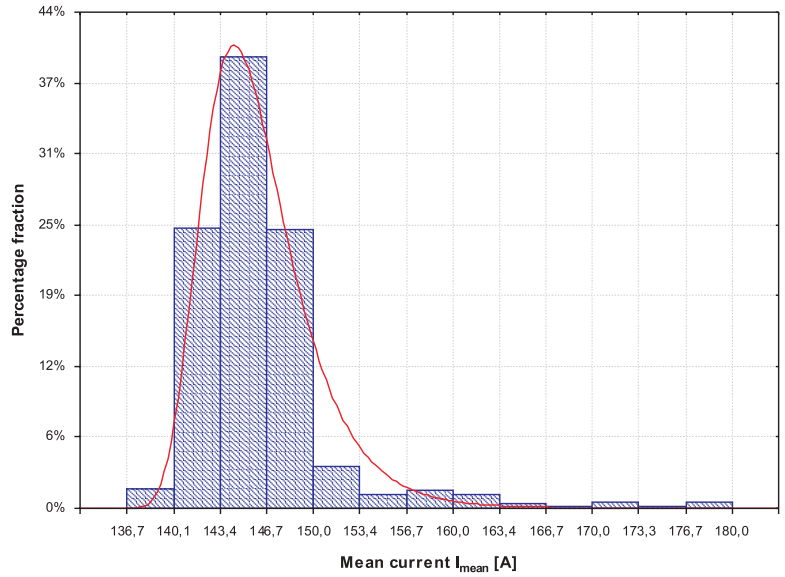

Fig. 2 Statistical distribution of mean current intensity $I_{\text {mean }}$, which occurs when starter drives engine crankshaft during the start-up

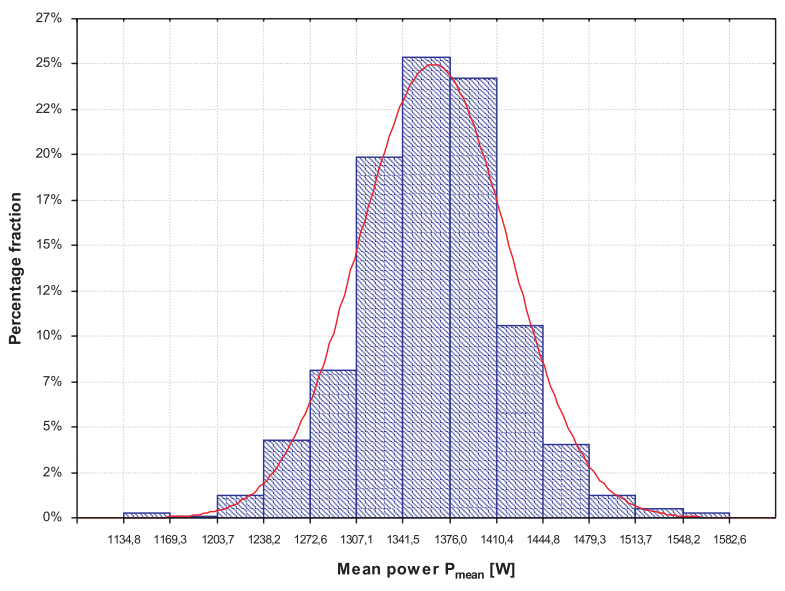

Fig. 4 Statistical distribution of power consumed $P_{\text {mean }}$ by the starter, which occurs when starter drives engine crankshaft during the start-up

meters and the other chosen engine and vehicle parameters. The following engine and vehicle parameters: temperature of cooling agent $\left(T_{\text {agent }}\right.$ in $\left.{ }^{\circ} \mathrm{C}\right)$ at the moment of the engine start-up, time of the engine operation ( $t_{\text {oper }}$ in $\mathrm{min}$ ) before its next start and the length of pauses in the vehicle operation ( $t_{\text {pause }}$ in $\mathrm{min}$ ), when the 4CT90 engine is switched off were chosen to calculate the correlation coefficients.

Figures 6-9 show scatter diagrams for chosen variables with the equation of regression function, for which the correlation coefficients $r \geq|0.4|$ which indicates a significant correlation between the analysed variables.

Figure 6 presents scatter diagrams for the maximal current intensity $I_{\max }$ in the first step of start-up and power consumed $P_{\max }$ by the starter and linear function of regression with the confidence interval for forecast mean observation with a prediction interval for single observation for the declared confidence level 


\begin{tabular}{|c|c|c|c|c|c|c|c|c|c|c|c|}
\hline & tax & $U_{\max }$ & max & nean & mean & mean & $t_{\text {start }}$ & $t_{\text {work }}$ & $T_{\text {agent }}$ & $t_{\text {oper }}$ & pause \\
\hline$I_{\text {max }}$ & 1.00 & & 88 & & & & & & & & 0.8 \\
\hline 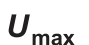 & 0.56 & 1.00 & T & .28 & 0.40 & 16 & & 10 & 0.39 & 0.14 & 0. \\
\hline & 88 & -0.1 & 0 & 0.10 & 0.4 & 32 & & -0 . & 0.2 & & 0. \\
\hline nea & 05 & -0.2 & 0 & 00 & 039 & 44 & & 00 & -0.69 & 10 & .70 \\
\hline 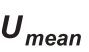 & 16 & 0 & 42 & -0.39 & 00 & 65 & 35 & -0.43 & 0.54 & 0. & -0.3 \\
\hline & & & & & & & & & & & 0.2 \\
\hline st & -0 & -0 & & 53 & 5 & & & .89 & 9 & & .65 \\
\hline & 0 & -0. & & 60 & 0.43 & & 89 & 1.00 & -0 & & -0.7 \\
\hline & & & & 0 & 0 & -0 & -0.59 & -0 & 18 & & -0.7 \\
\hline & 0.03 & . & & -0.13 & 0.19 & & -0.10 & 0.17 & 0.3 & 1.00 & 0. \\
\hline & .01 & 0.22 & 0.14 & .70 & -0.34 & 0.23 & 0.65 & -0.70 & -0.71 & -0.13 & 1.00 \\
\hline
\end{tabular}

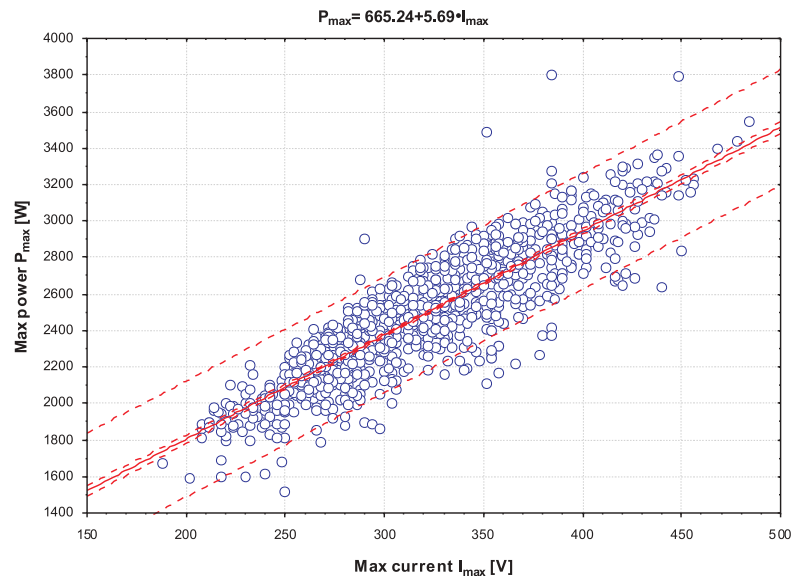

Fig. 6 Scatter diagram for the maximal current intensity $I_{\max }$ in first step of start-up and power consumed $P_{\max }$ by the starter

95\%. Statistical analysis using Statistica computer programme (declared significant level $\alpha=0.05$ ) showed that the random error of estimation for slope of the straight line is equal 0.091 and $t$-Student statistics $(t=62,58)$. The mean random deviation of a free term estimation is equal to 29.357 , the value of $t$-Student statistics $(t=22.660)$. The critical significant level $\alpha_{k r}$ is to equal 0.00 in both cases. It shows that the point estimation of regression coefficients is statistically significant. The value of the coefficient of determination $r^{2}$ is high and equals to 0.7756 , which proves that the line function of regression fits well to the data.

Also the relationship between the mean current intensity $I_{\text {mean }}$ and the mean power $P_{\text {mean }}$, which occur when the starter drives the engine crankshaft during the start-up seems to be linear what is shown in Fig. 7. The random error of estimation for slope of the straight line is equal to 0.3446 and the $t$-Student statistics $(t=14.092)$. The mean random deviation of a free term estimation is to equal 50.4198, the value of $t$-Student statistics $(t=12.940)$. The critical significant level $\alpha_{k r}$ is equal to 0.00 in both cases. It shows that the point estimation of regression coefficients is statistically significant. Unfortunately the value of the coefficient of determination $r^{2}$ is low and equals to 0.1990 which testifies weak variability of the mean power $P_{\text {mean }}$ line regression model. The values of analyzed parameters $\left(I_{\text {mean }}\right.$ and $\left.P_{\text {mean }}\right)$ which occur during the first daily engine start-ups (if $I_{\text {mean }}>155 \mathrm{~A}$ ) indicated influence on regression dependency for these parameters.

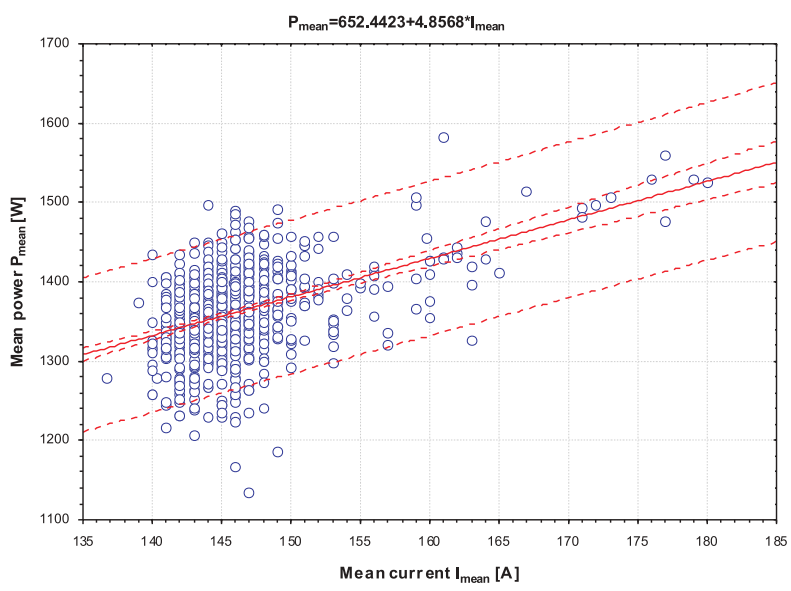

Fig. 7 Scatter diagram for the mean current intensity $I_{\text {mean }}$ and mean power $P_{\text {mean }}$, which occur when starter drives engine crankshaft during the start-up

The influence of values of the analyzed parameters which occur during the first daily engine start-ups is also observed in the relationship between the variable representing the engine thermal state (temperature $T_{\text {agent }}$ ) and the mean current $I_{\text {mean }}$ which occurs when the starter drives the engine crankshaft during the start-up. The value of the correlation coefficient $r_{\text {Tagent,Imean }}=-0.69$. It means that as the engine start-up temperature grows the movement resistance drops. Figure 8 shows scatter diagrams for the temperature of the cooling agent $T_{\text {agent }}$ at the moment of the engine start-up and the mean current intensity $I_{\text {mean }}$, which occurs when the starter drives the engine crankshaft during the start-up and the polynomial regression function. The statistical analysis showed that the mean random deviation of the free term estimation is equal to 1.632 , with 
the value of $t$-Student statistics $(t=114.78)$. The mean random error for the regression coefficient is equal to 0.000011 when $\left(T_{\text {agent }}\right)^{3}$, with the value of $t$-Student statistics $(t=-9.5302)$. The mean random error for the regression coefficient is equal to 0.00195 when $\left(T_{\text {agent }}\right)^{2}$, with the value of $t$-Student statistics $(t=11.6980)$ and the mean random deviation of estimation for the slope of the straight line is equal to 0.1052 when $T_{\text {agent }}$, with the value of $t$ Student statistics $(t=-15.9818)$. The critical significant level $\alpha_{k r}$ is equal to 0.00 in these cases. The estimation point of the regression coefficients is statistically significant. The value of the coefficient of determination $r^{2}$ is high and equals 0.6451 , which leads to the conclusion that the polynomial function of the regression fits the data well.

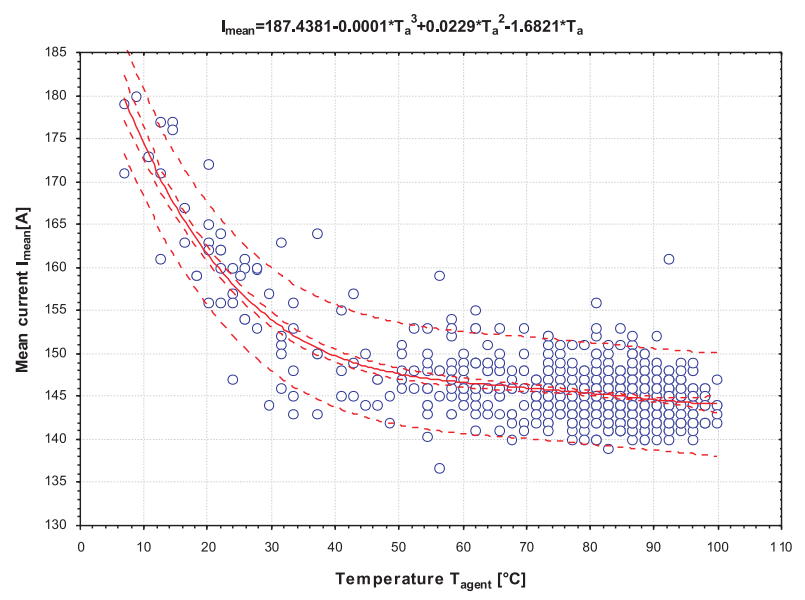

Fig. 8 Scatter diagram for the temperature of cooling agent $T_{\text {agent }}$ at the moment of engine start-up and mean current intensity $I_{\text {mean }}$, which occurs when starter drives engine crankshaft during the start-up

The correlation coefficient $r_{\text {Tagent,tstart }}=-0.59$ between the variable representing the engine thermal state (temperature $T_{\text {agent }}$ ) and the variable describing the time of its starting $t_{\text {start }}$ shows, which seems to be evident, that as the start-up temperature increases, the engine needs less time to start to operate independently at idle running. It is the result of the first spontaneous ignition of the fuel-air mixture in the engine cylinder. The scatter diagram with the regression curve for the temperature of the cooling agent $T_{\text {agent }}$ at the moment of the engine start-up and the engine start-up time $t_{\text {start }}$ shown in Fig. 9 confirms that regularity. The mean random deviation of the free term estimation is equal to 0.0632 , with the value of $t$-Student statistics $(t=23.00)$. The mean random error for the regression coefficient is equal to 0.00001 when $\left(T_{\text {agent }}\right)^{3}$, with the value of $t$-Student statistics $(t=-5.6092)$. The mean random error for the regression coefficient is equal to 0.000073 when $\left(T_{\text {agent }}\right)^{2}$, with the value of $t$-Student statistics $(t=7.0154)$ and the mean random deviation of estimation for the slope of the straight line is equal to 0.0039 when $T_{\text {agent }}$, with the value of $t$ Student statistics $(t=-10.0395)$. The critical significant level $\alpha_{k r}$ is equal to 0.00 in these cases. It shows that the point estimation of the regression coefficients is statistically significant. The value of the coefficient of determination $r^{2}$ is average and equals 0.6451 , which leads to the point that the polynomial function of regression fits the data satisfactorily.

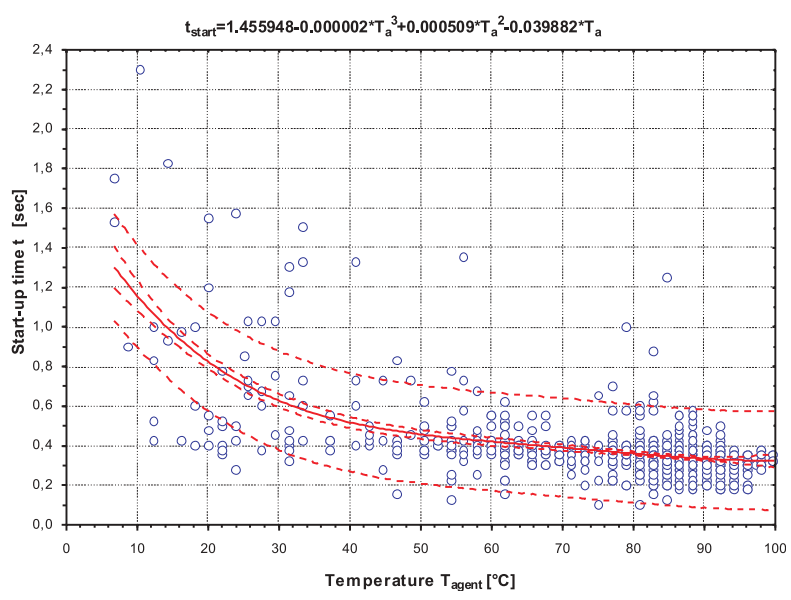

Fig. 9 Scatter diagram for the temperature of cooling agent $T_{\text {agent }}$ at the moment of engine start-up and engine start-p time $t_{\text {start }}$

The engine start-up time $t_{\text {start }}$ is connected with the mean current $I_{\text {mean }}$ which occurs when the starter drives the engine crankshaft during the start-up. The value of the correlation coefficient $r_{\text {Imean,tstart }}$ is equal to 0.53 . It is obvious that this connection is the result of the engine thermal state during the start-up. The decisive parameters that influence the engine thermal state are pauses in the vehicle operation $t_{\text {pause }}$, when the 4CT90 engine is switched off. It's shown by the correlation coefficient $r_{\text {tpause,Tagent }}=$ $=-0.71$. The mean current $I_{\text {mean }}$ and the time of engine start-up $t_{\text {start }}$ are relative to the pauses in the vehicle operation $t_{\text {pause }}$, when the 4CT90 engine is switched off. The correlation coefficients $r_{\text {tpauset,Imean }}$ is equal to 0.70 and $r_{\text {tpauset,start }}$ is equal to 0.65 . The influence of the pauses in vehicle operation $t_{\text {pause }}$ at the engine start-up time $t_{\text {start }}$ is shown in Fig. 10.

The statistical analysis showed that the random error of estimation for the slope of the straight line is equal to 0.00003 , with the $t$-Student statistics $(t=23.1154)$. The mean random deviation of the free term estimation is equal to 0.004242 , with the value of $t$-Student statistics $(t=83.2188)$. The critical significant level $\alpha_{k r}$ is equal to 0.00 in both cases. It shows that the estimation point of the regression coefficients is statistically significant. The value of the coefficient of determination $r^{2}$ is insignificant and equals 0.3241 , which provides the fact that the line function of regression doesn't fit the data. It is the result of the engine first daily start-ups which appear after at least 7 hours' pauses in the vehicle operation $t_{\text {pause }}$, when the 4CT90 engine is switched off.

Finally we should remark that the intensity of the mutual connections between the specific starter parameters and other chosen variables of the engine 4CT90 and LUBLIN III vehicle depend on the analyzed parameters occurring during the first daily start-ups. 


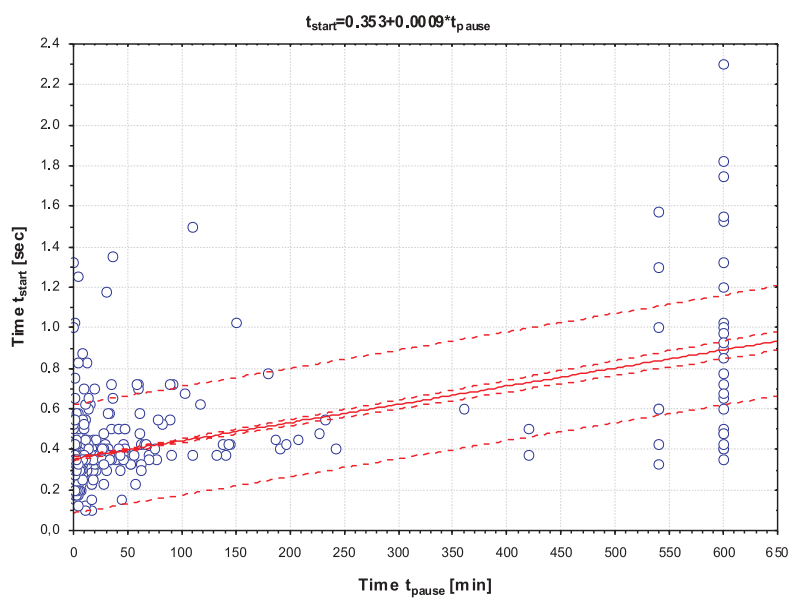

Fig. 10 Scatter diagram for the length of pauses in a vehicle operation $t_{\text {pause }}$, when the 4CT90 engine is switched off and engine start- up time $t_{\text {start }}$

\section{Summary}

Taking into account the correlation and the regression statistical analysis of the results of 4CT 90 engine start-up maintenance investigations we can state:

1. The crucial factor of vehicle work, influenced by the thermal state of the engine, the electrical parameters, is the time of pauses in vehicle operation, when the engine is switched off.

2. Proper organization of LUBLIN III vehicle trips and short time of pauses in the vehicle operation, when the engine is switched off, results in the fact that high temperatures occur of 4CT90 engine start-ups. That is why short start-up times are common and we can observe only unimportant overloads in engine start-up system.

3. The first daily start-ups are the separate group of start-ups which influence the correlation and the regression connections between the vehicle maintenance conditions and the electric starter parameters. The electric overloads during first daily start-ups are rather long and have the highest possible values.

\section{References}

[1] DROŹDZIEL P.: The investigations of the 4CT90 start-up engine during the operation of LUBLIN car (in Polish). The maintenance of combustion engines, no. 6. Publisher Szczecin University of Technology. Szczecin, 2002, p. 45-50.

[2] DROŹDZIEL P., LIŠČÁK Š.: The chosen problems of commercial truck maintenance, EDIS- Žilina University publisher, Žilina, 2005.

[3] KOZIEJ E.: The electric machine of vehicles (in Polish). Publisher WNT. Warszawa, 1986.

[4] MYSŁOWSKI J.: The start-up of a diesel engine (in Polish). Publisher WNT. Warszawa, 1996.

[5] PSZCZÓŁKOWSKI J.: The characteristics of start-up of diesel engines (in Polish). Publisher SEPP „Cogito”. Zbąszynek, 2004.

[6] WAJAND J. A., WAJAND J. T.: The combustion piston engine average - and high-speed (in Polish). Publisher WNT. Warszawa, 1997. 